\title{
Contribution of Job Stress and Self-Efficacy towards Burnout among Secondary School Teachers
}

Nurul Syazwanie Zakaria \& Hazalizah Hamzah

To Link this Article: http://dx.doi.org/10.6007/IJARBSS/v11-i10/11499

DOI:10.6007/IJARBSS/v11-i10/11499

Received: 25 August 2021, Revised: 27 September 2021, Accepted: 10 October 2021

Published Online: 28 October 2021

In-Text Citation: (Zakaria \& Hamzah, 2021)

To Cite this Article: Zakaria, N. S., \& Hamzah, H. (2021). Contribution of Job Stress and Self-Efficacy towards Burnout among Secondary School Teachers. International Journal of Academic Research in Business and Social Sciences, 11(10), $1227-1241$.

\section{Copyright: @ 2021 The Author(s)}

Published by Human Resource Management Academic Research Society (www.hrmars.com)

This article is published under the Creative Commons Attribution (CC BY 4.0) license. Anyone may reproduce, distribute, translate and create derivative works of this article (for both commercial and non-commercial purposes), subject to full attribution to the original publication and authors. The full terms of this license may be seen at: http://creativecommons.org/licences/by/4.0/legalcode

Vol. 11, No. 10, 2021, Pg. 1227 - 1241

Full Terms \& Conditions of access and use can be found at http://hrmars.com/index.php/pages/detail/publication-ethics 


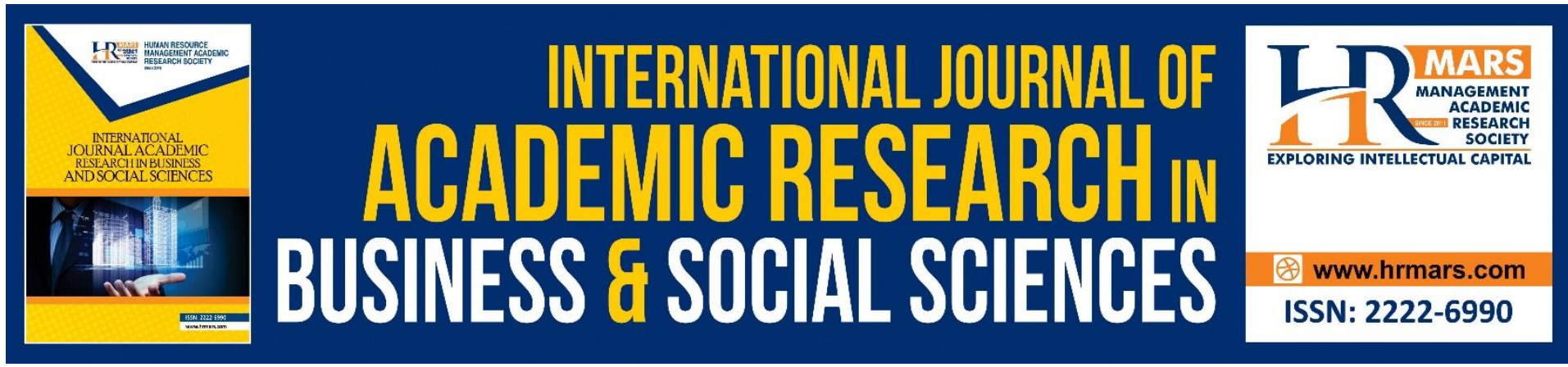

\title{
Contribution of Job Stress and Self-Efficacy towards Burnout among Secondary School Teachers
}

\author{
Nurul Syazwanie Zakaria \& Hazalizah Hamzah \\ Department of Psychology and Counselling, Faculty of Human Development, Universiti \\ Pendidikan Sultan Idris, 35900 Tanjong Malim, Perak Darul Ridzuan, Malaysia
}

\begin{abstract}
This study aimed to identify the contribution of job stress and self-efficacy towards burnout among secondary school teachers. The collection of data was done using survey method. The respondents were 94 secondary school teachers from selected school within Batang Padang District, Perak. The data were collected using a set of questionnaires, which contained the Effort Reward Imbalance Scale (ERI), Teacher's Sense of Efficacy Scale (TSES) and Maslach Burnout Inventory-Educators Survey (MBI-ES). The descriptive statistics was utilized to see the levels of variables involved and multiple regression was utilized to predict the contribution of job stress and self-efficacy towards burnout. The findings revealed that both variables of job stress and self-efficacy were significantly contributed to burnout among the secondary school teachers. Thus, it was proven that both of variables been measured could affect the burnout among the educators.
\end{abstract}

Keywords: Job stress, Self-efficacy, Burnout, Teachers Sense of Efficacy Scale, Effort Reward Imbalance Scale, Maslach Burnout Inventory-Educators Survey

\section{Introduction}

Nowadays, as people become more aware of the severity of burnout's implications in the education sector, various research has been done. For instance, Malik, Bjorkqvist, and Osteman (2017) conducted a study in Pakistan and Finland, Afsar, Govil, and Gupta (2015) studied within Uttar Pradesh population, and Wang et al (2015) conducted similar scope of study in China. These researches demonstrated the occurrence of burnout among teachers all around the world which has been the focus of attention until recently.

Betoret (2006) found burnouts as the result of the prolonged tension and many authors conceptualized it as the response of stress at the workplace. Burnout also characterized by three main dimensions, namely exhaustion, cynicism and feeling of reduced professional ability. Apart from this, Bumen (2010) found an inverse correlation between selfefficacy and burnout as Yu et al (2015) found self-efficacy as the mediating factor between job stress and burnout. Furthermore, Khani and Mirzaee (2015) found that self-efficacy as a mediator, played an important role in reducing burnout. In addition, before those studies been done, it was explained that self-efficacy beliefs as one of the factors that react in 
multiple ways within the human functioning such as the self-observation, self-judgement and self-reaction (Schunk, 1990).

Burnout issues among the teachers always being relate to various common causes. Shaheen and Mahmood (2016) burnout among the teachers found related to the locate, the reservation and the teaching level. Aside from the workload teachers face, several other factors gave been discovered to contribute to job stress, including the economic factors, personal variables such as gender, age, level of training and teaching period (Sabherwal, Ahuja, George and Handa, 2015; Ravichandran and Rajendran, 2007). Besides, Papasotiriou, Sidiropoulos, Ntanosa, Chalikias and Skordoulis (2018) discovered that burnout was related to the stages of professional satisfaction. Burnout also linked to student misbehaviour and job stress, according to Al-Asadi, Khalaf, Al-Waaly, Abed and Shami (2018). Moreover, Khani and Mirzaee (2015) found the role of self-efficacy in affecting burnout. However, the factors of self-efficacy were found less focused on the study that was done within Malaysia. Most of the existing work was founded done by other states.

Burnout also commonly related to the stress from the job. Instead of focusing on the environmental and social factors, most of the researchers highlighted the role of the people's beliefs in perceiving themselves to cope or to drown to stressful conditions. Steptoe and Poole (2016) the central construct within stress research is the ability in controlling the aversive experiences. The control was explained in many different forms, which are the behavioral control over stimulation sources, perception control and the coping responses, which are also known as cognitive control. Hence, this study included a variety of job stress and self-efficacy to discover the contributions of internal beliefs towards the burnout among the teachers.

Generally, this study was designed to measure the level of variables has been included which are the job stress, self-efficacy and burnout and also to investigate the contributions of job stress and the self- efficacy toward burnout among secondary school teachers.

\section{Literature Review \\ Job stress among Teachers}

A few researches focused on emphasizing on the job stress level among the teachers and highlighted on the various causes of stress found. Hadi, Naing, Daud, Nordin and Sulong (2009) the study intended to investigate the prevalence of stress and the factors that are associated with the contributions of stress among the teachers within Malaysia. The multiple linear regression was done and found that age, work duration and the psychological job demands were significantly associated with the stress level. In other hand, job-related factors did not contribute much to stress among secondary school teachers. While another study by Sabherwal et al. (2015) in their research discovered varying numbers of stress determinants including time pressures, lack of infrastructure student indiscipline, and poor pay prospects. Those found to be among the highest rank stressors found among workers and also revealed the finding that the respondents experienced an average low to moderate level of stress.

\section{Self-efficacy among Teachers}

In reviewing the research related to the self-efficacy among the teachers, only one latest paper found, which the researcher emphasized on the level of the secondary school teachers' self-efficacy. The research by Ali, Hassan and Jani (2017) was done to investigate the level of 
self-efficacy in teaching in secondary schools among Physical Education teachers in Kota Setar, Kedah Darul Aman. The findings demonstrate that there is a high level of self-efficacy found among the Physical Education teachers, which focus on the dimensions of students' involvement, instructional strategy and class management. That study also discovers that genders show no significant differences in self-efficacy level.

\section{Burnout among Teachers}

This subtopic focused on reviewing the research paper that is emphasizing on the burnout experiences. There were four studies found discovering the burnout levels among the teachers. The studies being discussed here used the assessment method in discovering the levels of burnouts and were done in a few different countries, Turkey, Uttar Pradesh Pakistan, Lahore and Finland.

Yilmaz, Altinkurt, Guner and Sen (2015) conducted a study to determine the burnout level among the teachers due to the emotional labour in the city centre of Kutahya, Turkey. The findings demonstrate that teachers have the highest burnout level when they experience emotional exhaustion. The high burnout level also associated with the lack of personal accomplishment and depersonalization. In addition, Afsar et al (2015) did research on the levels of burnout among the secondary school teacher, which referred to few demographic factors such age, gender, marital status and the place of living. Through the distribution of the Maslach Burnout Inventory, the t-test and analysis of variance reveal that the three dimensions of burnout were low. Besides, there is no significant difference between the level of burnout and the demographic factors being measured except for the place of living. Furthermore, Shaheen and Mahmood (2016), emphasised the role of gender, locale, job status, marital status, age, qualification, and level of teaching experience in the frequency of burnout among public school teachers in Lahore. However, the study confirmed the presence of burnout and job status, marital status and age found to not contribute to the occurrence of burnout among teachers. Malik et al (2017) conducted a study to determine the frequency of teachers who took sick leaves due to burnout. The study was conducted in Pakistan and Finland, which randomly obtained from 15 public universities' websites from both areas. A specific question was asked directly through the questionnaire in order to discover the measurement of sick leave due to burnout and the result yield that there was a significant frequent of sick leave due to burnout in Pakistan, which most of them were underage of 2635 years old. Through this finding, they also discover that young university teachers in that area were among high-risk category in experiencing burnout.

\section{Relationship between Job Stress and Burnout}

This subtopic reviewed the research on the relationship between the job stress and burnout. Two past researches were found related discussed on these and both were focusing on the burnout dimensions that was affected by the contributions of job stress.

Wang et. al (2015) conducted a study in Liaoning, China, to discover the relationship of occupational stress and burnout among 559 Chinese primary and secondary school. The findings revealed that the occupational stress is linked to all dimensions of burnout, which is emotional exhaustion, cynicism, and professional efficacy. Skaalvik and Skaalvik (2017) come out with the similar study focusing on the other dimensions of burnout. Their study discovered that three stressors involved, which were the discipline problems, low student 
motivation and value dissonance was actually contributing to or significantly relate with two dimensions of burnout, the depersonalization and personal accomplishments. It was also found that time pressure does not contribute to these two dimensions.

\section{Self-efficacy and Burnout among Teachers}

This section reviewed two similar studies on the relationship and contributions between the self-efficacy and burnout among the teachers. However, the newest research for this failed to be found.

Bumen (2010) aimed to measure the contributions of self-efficacy towards burnout among teachers in Izmir, Turkey. This study yields the results, which stated that there was an inverse correlation between variables being measured. Shoji et al. (2016) did research by using meta-analysis aimed to discover the self-efficacy and burnout associations. By reviewing and analysing 57 existing studies conducted among teachers and other professionals, they found that medium average effect size estimated for the associations of self-efficacy, burnout, and teachers found to show larger average effects as compared with others. They also focused on the components of the burnout involved and discovered that lacking accomplishment was the largest estimate of average effect.

\section{Contribution of Job Stress and self-efficacy towards Burnout among Teachers}

The objective of research by Yu et al (2015) was to examine the effect of work stress on job burnout, which focus on the mediating role of self-efficacy. According to the analysis, the researcher found that there was a significant correlation found between work stress, selfefficacy and burnout. In specific, it mentioned that the self-efficacy partially mediated the job stress towards burnout. In the same year, the similar study conducted by Khani and Mirzaee (2015), attempted to discover the contribution of self-efficacy and stressors towards teacher burnout in Iran. The findings demonstrated that the rise in stressors would cause the increase in burnout. Besides, the study discovered the important role of self-efficacy in reducing burnout by acting as mediator or moderator variable.

Betoret (2006) investigated the relationship among the teachers' occupational stressors, self-efficacy and burnout among 247 secondary school teachers in 21 different schools in Spanish and discovered that self-efficacy had an effect on the job stress and burnouts among teachers. In depth, the results explained that the high level of self-efficacy contributed to the low level of job stress and burnout and vice versa. Through these studies, the highlighted of the findings that could be seen was the role of the self-efficacy. Self-efficacy was not the only the causes of burnout among teacher but contributing as mediator to low level of burnout among teachers.

\section{Research Method}

This study used a survey design to collect the responses regarding contributions of job stress and self-efficacy towards burnouts. Paper and pencil survey that consists of standardized questionnaire which measure the variables included were distributed among the secondary school teachers. This study used Malay translated instruments. The instruments included were a short version of the Effort Reward Imbalance Scale (16 items) developed by Siegrist et.al (2004) and translated by Chong (2018), short versions of Teachers Sense of Efficacy Scale (12 items) developed by Tschannen-Moran and Woolfolk Hoy (2001) and translated by 
Dumpok (2016) and the Maslach Burnout Inventory-Educators Survey Scale (22 items) developed by (Maslach et al., 1996) and translated by (Ishak, 2015).

The population of this study was among 16 secondary school teachers in Batang Padang district within the urban area that are teaching various subjects. The sample size for this study was calculated using $G *$ Power 3.1.9.2 software, effect size estimated of $\mathrm{f} 2=0.15$, a power of 0.95 and the significance level is 0.05 . The estimated sample size is 146.20 per cent of incomplete data or missing is taken into consideration and the sample size for this study is 175. However, due to inaccurate timing in distributions of the questionnaire, a few teachers from the schools chosen were absent in their school due to examination sessions. Thus, a total of 94 people responded to the survey.

The selection of the participant used random cluster sampling. The clusters of participants from different schools in the Batang Padang District, which represents the population, were identified and five of the schools were chosen as the sample for this study. The schools chosen were SMK Katholik, SMK Choong Hua, SMK Methodist, SMK Hamid Khan and Sekolah Menengah Agama Daerah Batang Padang.

The data analysis of this study used the Statistical Package for the Social Sciences (SPSS) 20 Version to get the descriptive and inferential statistics. Descriptive analysis was run to describe the characteristic of the respondent and to test the hypothesis. The inferential analysis of this study was conducted using multiple regression. Sekaran and Bougie (2016), a few independent variables are used within the multiple regression analysis, which is to describe the variance in the dependent variable. Multiple regression was used to determine the predictive role of burnout by job stress and self-efficacy among the teachers.

\section{Results}

\section{Descriptive statistics}

The descriptive analysis within this research included the demographic background of the participants included age, gender and race. Descriptive analysis also included the levels of the three variables of job stress, self-efficacy and burnout.

Table 1 shows the characteristics of gender and race of participants involving 94 teachers from Batang Padang District aged from 25 to 56, whom 18.1\% were male and $81.9 \%$ were female. Female shows the highest participation in this study with the total number of 77 participations as compared to male with 17 total participations. The participants were from few different races, which are Malay, Chinese, Indian and others. The highest participation was from Malay teachers with the 77 number of participations (81.9\%), followed by Chinese with 10 participations (10.6\%), Indians with five participations (5.3\%) and the least participation from other races, which is not mentioned specifically, with two participations (2.1\%). 
Table 1. The Demographic Background of the Participants

\begin{tabular}{llcc}
\hline \multirow{2}{*}{ Demographic Background } & & Frequency & $\%$ \\
\cline { 2 - 4 } Gender & Male & 17 & 18.1 \\
& Female & 77 & 81.9 \\
\multirow{2}{*}{ Race } & Malay & 77 & 81.9 \\
& Chinese & 10 & 10.6 \\
& Indian & 5 & 5.3 \\
\hline Total & Others & 2 & 2.1 \\
\hline
\end{tabular}

Based on Table 2, the mean for job stress study using the Effort Reward Imbalance Scale (ERI) is ( $M=1.15, S D=0.40)$. According to the Effort Reward Imbalance Scale (ERI), ER=1 indicated an average between effort and reward, ER $<1$ indicated the imbalance in favour of rewards and $E R>1$ indicated an imbalance in favour of efforts.

Based on Table 3, ER>1 scored by most of the participants with the number of 58 participants $(61.7 \%)$ and followed by $E R<1$ with the number of 34 participants $(36.2 \%)$ and $E R=1$ scored the least among the participants, which is only by two participants (2.1\%). This result indicated that most of the participants experience stress within workplace, according to the highest score within the level of $E R>1$.

Table 2. Means and Standard Deviations for the Main Variables

\begin{tabular}{lcc}
\hline Variables & $M$ & $S D$ \\
\hline Job stress & 1.15 & 0.40 \\
Self-efficacy & 46.65 & 2.76 \\
Burnout & 68.79 & 5.64 \\
\hline
\end{tabular}

Table 3. Summary Table Level of Job Stress

\begin{tabular}{llcc}
\hline & & Frequency & $\%$ \\
\hline$E R=1$ & Balance between effort and reward & 2 & 2.1 \\
$E R<1$ & Imbalance in favour of reward & 34 & 36.2 \\
$E R>1$ & Imbalance in favour of effort & 58 & 61.7 \\
\hline Total & & 94 & 100 \\
\hline
\end{tabular}

The level of Self-Efficacy measured by Teachers Sense of Efficacy Scale (TSES), shown total mean of ( $M=46.65, S D=2.76)$. According to Table 4, it's shown that $91.5 \%$ of the teachers representing 86 out of 94 participants categorized as having a moderate level of self-efficacy and another $8.5 \%$ represent 8 participants were categorized as having low levels of selfefficacy. This is shown most of the participants were having a moderate level of self-efficacy. 
Table 4. Summary Table Level of Self-Efficacy

\begin{tabular}{lcc}
\hline & Frequency & $\%$ \\
\hline Low & 8 & 8.5 \\
Moderate & 86 & 91.5 \\
High & 0 & 0 \\
\hline Total & 94 & 100 \\
\hline
\end{tabular}

The level of burnout shown total mean of $(M=68.79, S D=5.64)$. The first domain has been measured was emotional exhaustion. According to Table 5, the highest categorization of emotional exhaustion found within the moderate level, which is 66 participants that represent $70.2 \%$ of the participants involved. Low level of emotional exhaustion showed the lowest score which is only by one of the participants and represent only $1.1 \%$ of the total. High level scored by 27 participants represents $28.7 \%$ of the total. This result shows that most of the teachers are facing moderate level emotional exhaustion based on the highest number of participants within moderate level.

The second domain has been measured is Depersonalization. Based on Table 5, there are only two categorizations of levels have been found which is moderate and high. The highest number of participants shown within the highest level of depersonalization, which is 65 participants, representing $69.1 \%$ of the total participants. Another 29 participants (30.9\%) shown having a moderate level of depersonalization.

The third domain is the reduced personal accomplishment. Referred to Table 5, the least number of participants shown within the lower level, which is only by five participants (5.3\%). Moderate and high-level show almost the same number of participants, which are 44 participants (46.8\%) and 45 participants $(47.9 \%)$ respectively. This shows that most of the teachers having a high level of reduced in personal accomplishment base on the highest number of participants shown within the high level.

Table 5. Summary Table Level of Burnout (Emotional Exhaustion, Depersonalization and Reduced Personal Accomplishment)

\begin{tabular}{llcc}
\hline Domains & Levels & Frequency & $\%$ \\
\hline \multirow{2}{*}{ EE } & Low & 1 & 1.1 \\
& Moderate & 66 & 70.2 \\
& High & 27 & 28.7 \\
\hline \multirow{2}{*}{ DP } & Low & 0 & 0 \\
& Moderate & 29 & 30.9 \\
& High & 65 & 69.1 \\
\hline \multirow{3}{*}{ Reduced PA } & Low & 5 & 5.3 \\
& Moderate & 44 & 46.8 \\
\hline Total & High & 45 & 47.9 \\
\hline
\end{tabular}




\section{Inferential Analyses}

The analyzation the results in investigating the contribution of job stress and self-efficacy towards burnout used multiple regression analysis. This study consists one major hypothesis and few sub hypotheses. The hypotheses were stated as follows:

H11: Job stress and self-efficacy will significantly contribute to burnout.

H11a: Job stress will significantly contribute to burnout

H11b: Self-efficacy will significantly contribute to burnout

Table 2 and 3 shown the result in multiple linear regression in predicting the burnout based on the job stress and self-efficacy. Based on the tables, a significant equation of regression was found, $\left(F(2,91)=11.86, p<0.000\right.$ with an $R^{2}$ of 0.21 . Participants' predicted burnout is equal to $33.90+5.22$ (Job Stress) +0.62 (Self-Efficacy).

According to the result, analysis of the main hypothesis has been concluded that that, the job stress significantly contributed to burnout (Beta $=0.37, t=3.94, p=0.000$ ) and selfefficacy also significantly contributed to burnout (Beta $=0.30, t=3.23, p=0.002$ ). The main hypotheses were accepted.

Table 6. ANOVA Table of Contribution of Job Stress and Self-Efficacy Towards Burnout

\begin{tabular}{lccccc} 
Frequency & $S S$ & $d f$ & $M S$ & $F$ & $p$ \\
\hline Regression & 610.83 & 2 & 305.41 & 13.05 & .000 \\
Residual & 2342.92 & 91 & 25.75 & & \\
\hline Total & 2953.75 & 93 & & & \\
\hline
\end{tabular}

Table 7. The Unstandardized and Standardized Regression Coefficient for the Variables

\begin{tabular}{lccccc}
\hline Variables & $B$ & Std. Error & Beta & $t$ & $p$ \\
\hline (constant) & 33.90 & 9.23 & & 3.68 & .000 \\
Job Stress & 5.22 & 1.33 & .369 & 3.94 & .000 \\
Self-efficacy & .620 & .192 & .303 & 3.23 & .002 \\
\hline
\end{tabular}

\section{Discussion and Research Implication}

\section{The level of Job Stress, Self-Efficacy and Burnout among Secondary School Teachers}

The objectives of this study were to measure the level of variables of job stress, self-efficacy and burnout among the secondary school teachers. This part will discuss on the level of job stress, self-efficacy and burnout. There will be a comparison and contradictions with the previous literature for each finding that will be discussed.

According to the results, all respondents found to have an imbalance between effort and reward $(E R \neq 1)$ except for only two of them. Respondents showed the highest score in effort reward imbalance in favour of effort $(E R>1)$. The imbalance between effort and reward indicated to the contribution of job stress within the workplace. This finding contributes to a contradiction with the sample of previous literature, which discover that the educators were 
actually facing an average low to moderate level of stress in their workplace (Sabherwal et al., 2015). Possible explanations for the findings may be due to various sources of stressors experienced by secondary school teachers such as the personal variables, including the levels of educations, years of teaching experiences and types of schools, which could significantly play role in the perception of many stress issues involved in teaching profession (Ravichandran and Rajendran, 2007).

Next, a moderate level shown within the self-efficacy measure. The respondents scored the highest within the moderate level of self-efficacy. The finding was slightly different with previous study where the self-efficacy among the secondary school teachers found to be high for all three domains been measured, which were student engagement, instructional strategies and classroom management (Ali et al., 2017).

Moreover, one dimension of burnout (emotional exhaustion) had a moderate level of burnout, whereas and two other aspects of burnout had high levels (depersonalization and personal accomplishment). As expected, the level of most of the dimensions of burnout was high as this study aimed the respondents with a great level of workloads. Malik et al. (2017) supports the findings as they discovered that university teachers were among the high-risk category in experiencing burnout. The highest burnout level faced by the teachers when experience emotional exhaustion, depersonalization and lacking in their personal accomplishments (Yilmaz et al., 2015). However, a contradiction of the findings also found as one of the previous literatures found low levels of burnout within all three dimensions been measured.

\section{Contributions of Job Stress and Self-Efficacy toward Burnout}

This study tried to identify as if the job stress and self-efficacy are the contributor of burnout among the secondary school teachers. First and foremost, according to the results, this current study found that job stress and self-efficacy did significantly contribute to burnout among the secondary school teachers been involved.

As predicted, job stress was a contributor to burnout. The association of job stress and burnout found in the sample evidence of previous literature. Wang et. al (2015) the findings of the current study been supported where it was found that the occupational stress in both primary and secondary school in China were actually proven to be associated with all dimensions of burnout. According to Skaalvik and Skaalvik (2017) instead of imbalance in effort and reward, the study found three stressors, which were the discipline problems, low motivation among the students and value dissonance significantly related to two dimensions of burnout (depersonalization and personal accomplishment).

The imbalance was found between effort and reward leading to job stress. The higher job stress, the higher probability of occurring burnout among the teachers. According to ERI Model, the efforts should be equalized by the exact reward and if the reciprocity being violated, the negative emotions or sustainable stress within the work role will be identified (Seigrist et. al., 2004).

In addition, the self-efficacy was found to be significantly predicted burnout. The findings of Bumen (2010) also flow in line with previous research which had found the inverse 
correlation between self-efficacy and burnout was measured. While the other study conducted by Shoji et. al (2016), found that there were moderate association between the two constructs of self-efficacy and burnout and concluded that a protective factor role played by self-efficacy against the component of burnout and a higher level of self-efficacy could be contributed by a low level of burnout.

Besides, the job stress and self-efficacy were found to be significantly predicted burnout. The findings were consistent with previous literature where they found a significant correlation between work stress, self-efficacy and burnout (Yu et al., 2015). In most of the related study found which the findings were in line with the current research, instead of being regarded as the predictor of burnout, self-efficacy was seen to play a mediating role between the job stress in controlling the level of burnout (Khani \& Mirzaee, 2015; Yu et al., 2015; Betoret, 2006).

\section{Implication of the Study}

This study conducted to find out the contributions of two variables, which were the job stress and self-efficacy, towards burnout. This study provided information that job stress and selfefficacy were actually contributed to the occurrences of burnout among the teachers through the findings of the analysis been done.

One of the implications of this study is the school authorities could become aware of the current situations of the educators within their respective schools. Besides, the school authorities will be able to come out with a resolution to improve the emotional state of the teachers either by conducting a campaign, holding more awareness program, increasing facilities to lower the burden of teachers or adding in training to help teachers with their selfimprovements.

Furthermore, this study could be added in one of the references for the other researchers who planned to conduct a similar study. This study could guide and give ideas so that they could come out with a better and clearer research.

\section{Conclusion}

In short, this research attempted to determine whether the job stress and self-efficacy acts as the predictors of burnout. Apart from that, the objectives of this study were to identify the levels of job stress, level of self-efficacy and also the level of burnout among the secondary school teachers. Besides, the objective also to predict the contribution of job stress and selfefficacy towards burnout among the secondary school teachers. The survey method used involving 94 respondents among secondary school teachers chosen through random cluster sampling. This research used Effort and Reward Imbalance Scale (ERI) that was translated by Chong (2018), Teacher's Sense of Efficacy Scale (TSES) that was translated by Dumpok (2016) and Maslach Burnout Inventory-Educators Survey (MBI-ES) that was translated by Ishak (2015). Two statistical analyses involved, which were descriptive and inferential analyses. The descriptive analysis conducted to identify the level of variability of job stress, self-efficacy and burnout while inferential analysis (using multiple regression) conducted to identify the contribution of job stress and self-efficacy towards burnout. The results from this research shown that both of the variables being tested, which are the job stress and self-efficacy were the significant predictor for burnout which led to the acceptance of the hypotheses made. 
This present study could give an insight into the current situation among the teachers and that future studies could be done in focusing on the solutions to the situation. Besides, could educate the teachers by providing a direct idea regarding their situations or conditions within their work environment or regarding the difficulties that they are facing. The education done through the results from what they have responded from the questionnaire. This could help them to open up with a clear view of oneself and came with the idea of improvement. This study also could inspire the school administrators to improve toward better and appropriate strategies in helping teachers' improvement like creating a better work environment, focusing on improving the teacher's motivation or self-improvement strategies. The outcomes of this study also could help in the continuous renewal of the study regarding these issues as the older results within this field of studies might not give the same interpretation of the current studies.

However, there are a few limitations of the current study were identified. The limitation was a small sample size. The study only focuses on one district within Perak and not either the whole state within Malaysia or the whole district within Perak. The findings might not be able to represent the situations within the whole populations and here the findings could only report the secondary school teachers' situation within only a limited area. Besides, this study limited in term of the response rate. The number of questionnaires been distributed was actually 200 but only 94 of them could be collected. The distribution of the questionnaire was done within the teachers' critical period (at the end of the year) where they got lots of works to settle and it might be the reason for the low response rate. Hence, the timing of the study also been one of the limitations within this study. A low response rate could cause the result to be affected.

There are several recommendations that would bring benefits for future research and could give an idea toward better findings. First, involve the study with a wide range of sample size. A large sample size could provide findings that are more accurate. Besides, a larger size of the sample could give a reliable result in representing the whole population being studied. Next is increasing the response rate by considering a good timing to distribute the questionnaire. For example, especially the study that involves teachers, it could be better to avoid distribution of the questionnaire during examination week. This is because most of the teachers might not available at the schools. Besides, avoid the end year since the teacher would have a lot to settle. The most suitable time could be the middle of the school session where the teachers will have enough time to spare in answering the questionnaire given.

\section{Acknowledgement}

The author would like to thank Universiti Pendidikan Sultan Idris and each school from Batang Padang districts for being involved in conducting this study.

\section{Corresponding Author}

The author would like to express a deep and earnest gratitude to respectful Academic Supervisor, Associate Professor Dr. Hazalizah Hamzah from the Department of Psychology and Counselling, Faculty of Human Development, Universiti Pendidikan Sultan Idris, Tanjong Malim, Perak, for all the hard works and guidance in making this study successful. Sincere gratefulness also goes to all the secondary school teachers who voluntarily offered a great contribution in data collection. 


\section{References}

Dumpok, A. R. (2016). Konstruk instrumen penilaian efikasi kendiri guru Pendidikan Jasmani. (Unpublished masters thesis). Universiti Pendidikan Sultan Idris, Perak.

Abel, M. H., \& Sewell, J. (1999). Stress and burnout in rural and urban secondary school teachers. Journal of Educational Research, 92(5), 287-293. doi: 10.1080/00220679909597608

Ishak, A. H. (2015). Burnout dan tekanan kerja di kalangan guru: satu kajian terhadap guru-guru sekolah menengah daerah Hulu Langat. (Unpublished masters thesis). Universiti Pendidikan Sultan Idris, Perak.

Hadi, A. A., Naing, N. N., Daud, A., Nordin, R., \& Sulong, M. R. (2009). Prevalence and factors associated with stress among secondary school teachers in Kota Bharu, Kelantan Malaysia. Southeast Asian Journal of Tropical Medical Public Health, 40(6), 13.

Bandura, A. (1986). Social foundations of thoughts and action: A social cognitive theory. Englewood Cliffs, NJ: Prentice-Hall. 1-3.

Bandura, A. (1994). Social cognitive theory and exercise of control over HIV infection. In Preventing AIDS (pp. 25-59). Springer, Boston, MA.

Bandura, A. (2010). Self-efficacy. The Corsini encyclopedia of psychology, 1-3.

Betoret, F. D. (2006). Stressors, self-efficacy, coping resources, and burnout among secondary school teachers in Spain. Educational psychology, 26(4), 519-539.

Bumen, N. T. (2010). The Relationship between demographics, self-efficacy, and burnout among teachers. Eurasian Journal of Educational Research (EJER), (40).

Chong. (2018). To predict the quality of work life by using the job stress and perceived sosial support among teachers in elite secondary schools around the district of Melaka Tengah. (Unpublished final year project). Universiti Pendidikan Sultan Idris, Perak.

Afsar, F., Govil, D. P., \& Gupta, S. (2015). Burnout among secondary school teachers with reference to certain demographic variables. European Academic Research Vol. II, Issue $11,14338-14349$.

Shaheen, F., \& Mahmood, N. (2016). Demographic variables as determinants of emotional burnout among public school teachers. Journal of Research and Reflections in Education, 10(1), 37-50.

Freeman, B., \& Coll K. M. (1997). Factor structure of the Role Questionnaire (RQ): A study of high school counselors. Measurement and Evaluation in Counseling and Development, 30, 32-39.

Al-Asadi, J., Khalaf, S., Al-Waaly, A., Abed, A., \& Shami, S. (2018). Burnout among primary school teachers in Iraq: prevalence and risk factors. Eastern Mediterranean Health Journal, 24(3), 262-268.

Kourmousi, N., \& Alexopoulos, E. C. (2016). Stress sources and manifestations in a nationwide sample of pre-primary, primary, and secondary educators in Greece. Frontiers in public health, 4, 73.

Ling, T. P., Pihie, Z. A. L., Asimirin, S., \& Fooi, F. S. (2015). The validity and reliability of teacher efficacy revisited in Malaysia secondary schools. Journal of Studies in Education, 5(1), 27-35.

Litt, M. D., \& Turk, D. C. (2015). Sources of stress and dissatisfaction in experienced high school teachers. The Journal of Educational Research, 78(3), 178-185.

Maslach, C. (1998). A multidimensional theory of burnout. Theories of Organizational Stress, 68,85 .

Maslach, C., \& Jackson, S. (1986). Maslach burnout inventory manual. Palo Alto: Conculting 
Psychologists Press.

Maslach, C., Jackson, S. E., \& Leiter, M. P. (1996). Maslach burnout inventory manual (Vol. 4). Palo Alto, CA: Consulting Psychologists Press.

Malik, N. A., Bjorkqvist, K., \& Österman, K. (2017). Sick-Leave due to burnout among university teachers in Pakistan and Finland and its psychosocial concomitants. European Journal of Social Science Education and Research, 4(4), 203-212.

Alrefaei, N. A. (2015). Teachers' sense of efficacy: Examining the relationship of teacher efficacy and student achievement. (Doctoral dissertation, University of Arkansas, Fayetteville). Retrieved from https://scholarworks.uark.edu/etd/1192/

Papasotiriou, E., Sidiropoulos, G., Ntanosa, S., Chalikias, M., \& Skordoulis, M. (2018). The relationship between professional burnout and satisfaction: A case study for physical education teachers in a Greek urban area. Serbian Journal of Management, 13(2) , 353363.

Ravichandran, R., \& Rajendran, R. (2007). Perceived sources of stress among the teachers. Journal of Indian Academy of Applied Psychology, 33(1), 133-136.

Khani, R., \& Mirzaee, A. (2015). How do self-efficacy, contextual variables and stressors affect teacher burnout in an EFL context? Educational Psychology, 35(1), 93-109.

Sabherwal, N., Ahuja, D., George, M., \& Handa, A. (2015). A study on occupational stress among faculty members in higher education institutions in Pune. SIMS Journal of Management Research, 1(1), 18-23.

Schaufeli, W. B. (2017). 'Burnout: A short socio-cultural history', in Neckel, S., Schaffner, A. K., \& Wagner, G. (Eds.) Burnout, fatigue, exhaustion. Cham, Switzerland: Springer Nature, 105-127.

Schunk, D. H. (1990). Goal setting and self-efficacy during self-regulatedlearning. Educational Psychologist, 25, 71-86.

Sekaran, U., \& Bougie, R. (2016). Research methods for business: A skill building approach (7th ed.). West Sussex, UK: John Wiley \& Sons.

Shaughnessy, J. J., Zechmeister, E. B. \& Zechmeister, J. S. (2012). Research methods in Psychology. New York: Michael Sugarman.

Shoji, K., Cieslak, R., Smoktunowicz, E., Rogala, A., Benight, C. C., \& Luszczynska, A. (2016). Associations between job burnout and self-efficacy: a meta-analysis. Anxiety, Stress, \& Coping, 29(4), 367-386.

Siegrist, J. (1996). Adverse health effects of high-effort/low-reward conditions. Journal of Occupational Health Psychology 1, 27-41.

Siegrist, J. (2012). Effort-reward imbalance at work: Theory, measurement and evidence. University Düsseldorf, Düsseldorf: Department of Medical Sociology.

Siegrist, J., Starke, D., Chandola, T., Godin, I., Marmot, M., Niedhammer, I., \& Peter, R. (2004). The measurement of effort-reward imbalance at work: European comparisons. Social science \& medicine, 58(8), 1483-1499.

Skaalvik, E. M., \& Skaalvik, S. (2017). Dimensions of teacher burnout: Relations with potential stressors at school. Social Psychology of Education, 20(4), 775-790.

Stanhope, J. (2017). Effort-Reward Imbalance questionnaire. Occupational Medicine, 67(4), 314-315.

Stansfield, S. R. (2011). Occupation and mental health in a national UK survey. Soc. Psychiatry Psychiatr. Epidemiol. 46, 101-110.

Steptoe, A., \& Poole, L. (2016). 'Control and stress', in Steptoe, A., \& Poole, L. Stress: Concepts, Cognition, Emotion, and Behavior, Academic Press, 73-80. 
Suhane, A. (2018). Unit-14 Statistics and probability. IGNOU.

Ali, S. K., Che Hassan, M. Z., \& Jani, J. (2017). Efikasi kendiri guru pendidikan jasmani terhadap pelaksanaan pengajaran mata pelajaran pendidikan jasmani. JuKu: Jurnal Kurikulum \& Pengajaran Asia Pasifik, 2(3), 43-51.

Tella, A. (2015). Electronic and paper-based data collection methods in library and information science research: A comparative analyses. New Library World, 116(9/10), 588-609.

Tschannen-Moran, M., \& Woolfolk Hoy, A. (2001). Teacher efficacy: Capturing and elusive construct. Teaching and Teacher Education, 17, 783-805.

Wang, Y., Ramos, A., Wu, H., Liu, L., Yang, X., Wang, J., \& Wang, L. (2015). Relationship between occupational stress and burnout among Chinese teachers: a cross-sectional survey in Liaoning, China. International Archives of Occupational and Environmental Health, 88(5), 589-597.

Yilmaz, K., Altinkurt, Y., Guner, M., \& Sen, B. (2015). The relationship between teachers' emotional labor and burnout level. Eurasian Journal of Educational Research, 59, 7590.

Yu, X., Wang, P., Zhai, X., Dai, H., \& Yang, Q. (2015). The effect of work stress on job burnout among teachers: The mediating role of self-efficacy. Social Indicators Research, 122(3), 701-708. 